
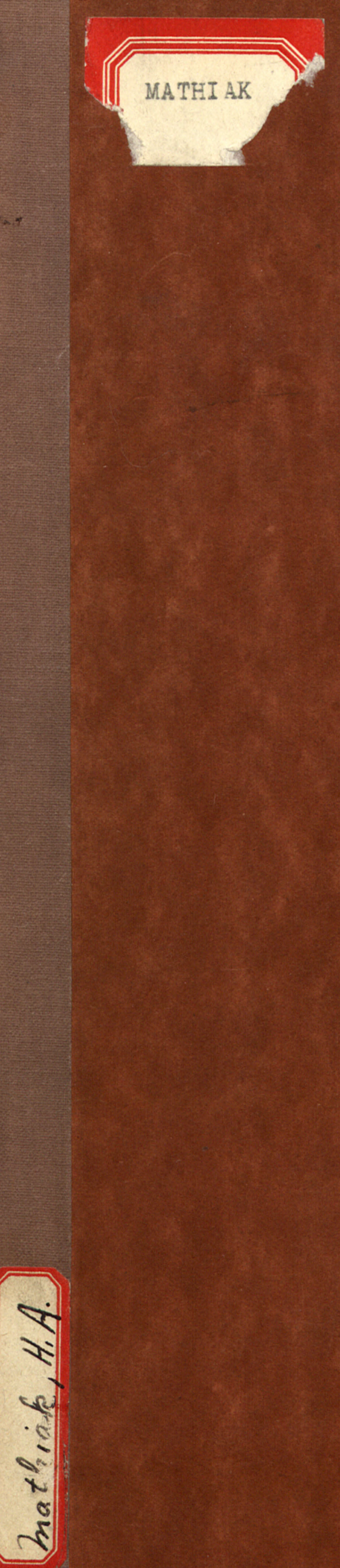




\title{
A KEY TO THE HAIRS \\ OF THE MAMMALS \\ OF SOUTHERN MICHIGAN
}

\author{
by \\ Harold A. Mathiak
}

A dissertation submitted in partial fulfillment of the requirements for the degree of Master of Forestry in the University of Michigan. 


\section{ACKNOWLEDGMENTS}

Grateful acknowledgment is made to

H. M. Wight under whose supervision

this work was done. Thanks are also

due to the School of Forestry and

Conservation for supilying the

materials used in the experimental

phases of the work. 


\section{TABLE OF CONTENTS}

Introduction - . • . . - . . . . . 1

Hair Structure • • • • • • . • . . 4

Hair Types • • • • • • • • • • • • 7

Tactile hairs • • • • • . • . 7

Guard hairs . . • . . . . . 8

Fur hairs • . . . . . . . . . 8

Intermediate hairs • • • • • . $~ .9$

Technique • • • • • • • • • • 10

Cross-sectioning • • • • • • • • . 11

Scale examination . . . . . . 13

Key • • • • • • • • • • • • • • 15

Division I . . . . . . . . . 17

Division II . . . . . . . . . $2 I$

Literature Cited • • • • • • • • • 29

Illustrations • • • • • • • • • • 30

Appendix • • • • • • • • • • • 39 


\section{INTRODUCTION}

Hair, universal to almost all mammals, occupies an important place in biological studies. Food habits research involving fecal and pellet analysis probably best illustrate the use to which a knowledge of hairs can be put in wildilfe management. Hairs are, of course, found under many different circumstances. A cluster of hairs may be the only clew evident where a case of predation has taken place or various types of accident may have occured. Other conditions under which hairs may be found include hairs left in sprung traps or dislodged at the entrances to caves or dens. The authenticity of fur garments is often questioned, but this wider problem is not considered in this discussion.

There is a paucity of information which is sufficiently specific to enable a beginner to identify hairs of even the common mammals. The practice now prevalling is for a person not familiar with hairs to identify an unknown sample by the laborious, hit-or-miss process of comaring the unknown with a known sample. It is hoped that this key will make it possible for the beginner to identify many hairs without resorting to the comparison method. After observing specific characters mentioned in the key, it probably will also be possible

1. The writer has studied only the hairs of the mammals mentioned in the key. Generalizations are mostly concerned with this limited group of mammals and can hardly be expected to be true in all cases for areas with a different fauna. 
to recognize certain hairs without the use of the key.

Only the hairs of the mammals of southern Michigan (south of township line 16) are treated in this key. A few mammals rarely found on this area have been omitted. Distinguishing criteria given in the key are not necessarily valid for related species of even adjolning areas although it is anticipated that the key may be of some value for identifying hairs of mammals not found on the area considered in this paper. Domestic as well as the wild mammals have been included in the key although they have been described only sufficiently to distinguish their hairs from those of the wild mammals. Some species have been grouped together even though their hairs are probably distinct enough to permit identification down to species especially if the fur hairs were studied in more detail. Others have been grouped because of the close resemblance between their hairs.

There may be three or more types of hairs existing in considerable numbers on any individual mammal. The hairs within each type vary chiefly with the season of the year (primeness) and with the age of the mammal. Young mammals are at first provided with a fine, fluffy coat of hairs: The writer had no opportunity to study these hairs so that it is not knom whether or not they can be identified by means of the key. However, at the age of several weeks, hairs characteristic of the adults appear which, although small at first, are similar in structure to hairs of the adults and do not merit special 
consideration. Gunn $(4,5)$ after intensive studies of the differences between prime and unprime pelts states, "-the conclusion may be drawn that the differences represent merely different phases in the life cycle of the hair." Hadwen $(6,7)$ in studying the color changes in snowshoe hares found that the whitening of the hairs was due to a blanching of the pigments of the hair shaft and not-to the growth of an entirely new coat of white hairs: By clipping and dyeing some brown hairs, he was able to identify these same hairs after they had turned white. A degeneration of mature hairs, particularly noticeable in clipped hairs, was observed in the white snowshoe rabbits. These frayed hairs, which he called kempy fibers, are never present to the exclusion of the easily recognized sound hairs. Many other species of mammals have stronger hairs which are not likely to be thus destroyed.

Other writers, Allen ( 1 ) and Grange (3) contend that the whitening of the hairs is due to the growth of a new coat of white hairs. Whatever the case may be, the changes in a hair becoming prime, or white in the case of the variable mammals, is essentially a change in the pigmentation of the hairs the gross structure not being materially altered. But pigmentation has not been made a major feature of the key owing to a further reason, the diversity of pigment granule arrangement in the hairs of certain species. Pigments may be uniformly distributed throughout the cortex, concentrated in longitudinal bands, or lacking entirely. There is also much variation in the size 
and color of the pigment granule itself. A third factor is the diterioration they sometimes undergo if subjected to weathering or to the action of digestive juices.

The hairs from the back, sides, and belly are usually similar in structure. The color pattern may be identical in these regions, or as is often the case, lighter or differently colored on the ventral surface. Undoubtedly most hair analyses will be concerned with body hairs inasmuch as they constitute such a large percentage of the total numbersof hairs. Head, leg, and tail hairs may be of the same or of totally different structure. Head hairs of average size are sometimes considerably flattened and of greater diameter than any of the body hairs.

\section{HAIR STRUCTURE}

Description and classification of the variations in hair structure and form are taken with certain modifications from the data provided by Dr. L. A. Hausman. $(9,10,11)$. The parts of a hair are the root, the bulbous portion situated beneath the surface of the skin, and the shaft, the portion extending above the surface, The shaft of a typical hair is composed of three elements, the medulla, cortex, and cuticle (Figs. 1,2). The medulla is a central core or pith composed of shrunken cells of irregular shape, air chambers, and pigments. Three types of medullae are referred to in the key. The discontinuoas medulla is one in which 1solated individual chambers can be seen, and the chambers lie in a single row. This type of 
medulla is most commonly found in fur hairs and may occupy a large proportion of the shaft (cortex relatively thin as seen in Fig. 3) or a smaller percentage of the shaft (cortex relatively thick as seen in Fig. 4). Masses of melanin or pigment granules dispersed between the medullary chambers may cause the medulla to appear continuous at first glance(Fig. 4). The continuous medulla is characteristic of guard hairs although it is found in other types of hairs also. A few variations of the continuous medulla are shown in Figs. 5-7. Fig. 5 illustrates the outline of a nodose continuous medulla or one of irregular construction in contrast to the homogeneous medulla (Fig. 6) which has a more uniform,granular construction. The nodose medulla is well exemplified by the larger hairs of many rodents. The medulla is fragmental when it consists of unconnected fragments of varying length (Fig. 8). Hairs of some species commonly have a continuous medulla in part of the shaft and a fragmental medulla in the remainder. Or a continuous nodose medulla frequently becomes discontinuous for a short distance before it disappears at the tip of the hair. Guard or intermediate hairs of the rodents may have a compound medulla which is most common in this order of mammals. This type of medulla is shown at different regions of a hair in Figs. 9 and 10. The nodose continuous medulla may be so pigmented as to produce basically the same effect of alternating masses of melanin. To conventence many future references to these types of medullae, they have been called the "rodent base". 
The rodent base is usually seen in the basal portion of the hair, and its appearance varies with the character of the pigment granules in the cortex and medulla. After becoming familiar with the rodent base, it can be recognized in hairs with a heavily pigmented cortex or hairs in which the melanin of the meduila is lacking. The rodent base may also be seen in the guard hairs of rabbits. Only very rarely are the medullae of hairs in other groups of mammals so constructed as to produce the rodent base effect.

The cortex is a hyaline layer of fusiform cells surrounding the medulla. Its cells are transparent and partially fused together so that they cannot be readily seen unless treated with acids or alkalies. The cortex contains air spaces and pigments which are partially responsible for the characteristic colors of hairs. The pigments may be either in the cells themselves or in the spaces between the cells. Pigments are diffuse or in the form of granules, the latter being the more common of the two. Usually there is diffuse pigment associated with pigment granules but only to a minor extent (Boyd,2).

A single layer of flattened, transparent cells constitute the cuticle or outermost layer of the.shaft. Cuticular scales fall into two groups, imbricate scales (Fig. 11) and coronal scales (Fig. 12). An caronazte scale extends completely around the shaft while a single imbricate scale extends only part way around the shaft with the base of each scale beneath the distal portion of the adjoining scale. 


\section{HAIR TYPES}

Hairs can roughly be divided into four groups: specialized hairs, guard hairs, fur hairs, and hairs intermediate to guard and fur hairs. Many oddities in specialized hairs can be seen in certain mammals throughout the world. The quills of the porcupine found in northern Michigan are markedly dissimilar to any of the hairs of mammals of southern Michigan. Tactile hairs or whiskers, a form of specialized hair common to practically all mammals, are found on the head or sometimes on the forlegs. Tactile hairs can be told from all other types of hairs by the following characteristics: They are the only hairs which constantly decrease in diameter from the base to the tip of the hair. All other hairs, excluding hairs with nodes and internodes, taper toward both the base and the tip. The medulla is often lacking. When present, it is never a conspicuous element of the hair, but is much reduced in size. Typically it is continuous at the base, but soon becomes fragmental and disappears. These hairs are also characteized by an extremely long drawn-out tip which is not found in other hairs of corresponding size. Lross sections are circular or nearly so in all cases. Generally the cortex contains dark pigment granules which may be so numerous as to conceal the medulla. There is considerable range in the size of tactile hairs from any one individual, the largest hairs often being longer and larger in diameter than any of the body hairs. Large tactile hairs are made conspicuous by their size in pellets and feces 
containing large quantities of hairs of the smaller mammals. Tactile hairs are readily recognized as such and, being very similar in structure between the different species, they are of no value for identification purposes. Therefore these hairs have not been included in the key or taken into account in the following discussion.

Guard Hairs. The largest hairs in diameter and length are the guard or protective hairs. The medulla of guard hairs is generally continuous. A typical form of guard hair is one which is fusiform in shape or of largest diameter near the mid-region and tapers toward both ends of the hair. Cross sections of guard hairs may assume a variety of shapes never found in fur hairs. The scales are often closely appressed for the entire length of guard hairs, giving them a high luster. Short guard hairs may exhibit very much taper while long guard hairs sometimes show very little taper.

Fur Hairs. Fur hairs are the finest hairs of a pelt and constitute what is known as the underfur. They often have a discontinuous medulla, prominent scales, and are never enlarged at their distal ends. Many fur hairs have nodes and internodes, an internode being a constriction of the shaft (Fig.13) while a node is that portion of the shaft lying between two internodes. Pigmentation, except at the tip of the hair, is generally confined to the medulla, with a lesser number of species having pigments in the cortex of the hairs. Except at internodes and the extremeties, fur hairs have very little 
taper, the edges appearing parallel under the microscope. Intermediate Hairs. These are the intergrades between fur and guard hairs. A common type is one enlarged in the distal portion while the basal part is finer and similar to fur hairs in structure. These hairs have been called pile hairs in rabbits and rodents. Hair structure may or may not indicate taxonomic relationships. In some genera, such as Mustela, the hairs of the various species appear identical except in size. In other instarces, hairs of widely unrelated species appear almost identical. Thus the long dark guard hairs of the brown rat appear very similar to some leg hairs of the skunk, excepting that the scales at the base of the hairs are transverse in the skunk and longitudinally disposed in the brown rat.

Size is of some value in hair identification. For each species there is a maximum diameter and length beyond which it is unlikely that larger hairs will be found. Thus given a hair of a certain length, the mammals never having hairs that long are elininated from further consideration. For instance, a hair $40 \mathrm{~mm}$. long belonging to the genus Mustela coilld not be referred to the least weasel because it never has hairs that long. However, a similar hair only $10 \mathrm{~mm}$. long could have come from the back of a least weasel or the head or legs of a mink or New York weasel.

The key is based almost entirely on guard and intermediate hairs, for they are easier to handle and more characteristic 
of the species. The coarser hairs are not injured as much as fur hairs by the action of digestive juices although even guard hairs may be broken by mechanical forces. Fur hairs, having a thinier cortex, are often found to be severely macerated and discolored in feces and pellets, the medulla frequently being totally blackened, occasionly a sample of fur hairs is found without any guard hairs being present. In general, though, fur hairs are so fine that they probably escape notice unless if they are quite abundant in which case guard hairs are likely to be present also.

\section{TECHNIQUE}

Certain equipment is needed for the efficient microscopical examination of hairs. The microscope should be provided with an ocular micrometer, Abbe condenser, and a daylight lamp. A mechanical stage is almost a necessity for proper manipulation of the hair while under observation, for it is desirable that any portion of a hair can be brought into the microscopic field quickly and easily. Measurements of diameter in micra (one micron is equal to $1 / 1,000$ of a millimeter) are taken with an ocular mierometer. Details as to the use of the microscope and its acessories can be found in any of the textbooks of micrology or microtechnique. Except when very dirty, hairs can be mounted directly in an essential oil (oil of cloves, oil of bergamot, etc.) or in xylene for longitudinal examination. These reagents clear or make the elements of the 
hair more clearly visible under the microscope. sylene is a good medium to use, for after the hairs have been examined, the slide and cover glass can be wiped clean with a dry cloth, thus eliminating the task of washing the slides. The room should be well ventilated, for xylene evaporates readily and has a penetrating, slightly disagreeable odor. Only transmitted light need be used in the examination of hairs and cross sections. Dirty hairs can be washed in a voldtile, grease disoliving reagent such as alcohol, ether, or carbontetrachloride.

Cross-Sectioning Hairs. To successfully use the key, it is frequently imperative that the character of the cross sections be known, either at a stated region of the hair or serially along the entire length of the hair. The cross sections can be obtained by the method previously reported by the writer.*The serial drawings of cross sections (Figs. 26-35) are shown as they appeared in individual hairs while the composite illustations (Figs. 22-25) represent cross sections of a group of hairs. They are to show the general shape and proportions of the cortex and medulla rather than to give the exact shape of any hair which might be cross sectioned. The serial sections have usually been taken at uniform distances along the hair. Cross sections of hairs which are enlarged only in the distalend show one or two sections of the finer base and the remainder are of the enlarged portion.

* Mathiak, H. A. A Rapid Method of Cross-Sectioning Mammalian Hairs. Jour. Wild. Management. (Accepted for publication). (See Appendix). 
The drawings are of cross sections taken at regions some distance apart. Therefore where two adjacent cross sections are shown to vary widely in shape, in the actual hair, intergradations between the two shapes must have existed. uross sections of short hairs should be taken at smaller intervals than in long hairs since the shape of the cross sections may change much more quickly in a given distance. All drawings progress from the base of the hair at the left to the tip at the right. Identification is facilitated by performing the various operations in a standard, systematic order. Then imbedding entire hairs, the base of the hair is conveniently grasped with a fine-pointed forceps and the hair laid on the celluloid with its base to the right end of the stick of balsa wood. After the sections have been sliced, they can be placed on the slide in serial order and examined from the base to the tip of the hair, comparing them with the Figures when necessary. Usually the basal and distal ends of a hair can be determined with the naked eye or with the aid of a hand lens. Most of the hairs with noticeable taper are of maximum diameter somewhere in the distal half of the hair although tail hairs are sometimes a little coarser in the basal half. Many times the terminus of the hair at the base is conspicuously heavier than the tip which ends in a fine point. Some hairs are of equal fineness at the base and tip. Then the microscope must be resorted to. The distal end of a hair is told by the fact that it is always the distal portion of an individual scale 
that always overlaps the basal end of the adjacent scale. The basal end of the hair either terminates with a broken surface or in a bulbous root.

Scale Examination. Saxinger and Herzog, both referred to by Hardy ( 8 ), developed a quick method for determining the form of cuticular scales. Their method is to place a thin coating of a plastic material on a slide, press the hairs into the plastic substance, and allow it to harden. The hairs are then removed and the negative impression of the scales thus produced examined under the micriscope. The celluloid solution used in Cross-sectioning hairs serves weil as the plastic material. This operation is not difficult to perform after a little experimentation with the viscosity of solution used and the time to lay the hairs on the celluloid. It does not matter how hard the celluloid becomes since only the lower portion of the hair is in contact with it and the hair can be removed without difficulty.

Hardy (8) and Manby $(12,13)$ present modifications of this method by which positive impressions of the scales can be studied. The simplest method given is to attach the ends of the hairs to the slide so that the hair is in contact with the slide. A drop of celluloid solution is placed along the hair and allowed to dry. The hair is then torn out, the slide inverted, and the impression studied with a microscope. To prevent breaking, the hairs should be pulled out of the celluloid before it becomes too hard. These methods were developed 
primcipally to facilitate photography of the scales which requires that the images be sharply defined.

For the purpose of the key, it is not essential to obtain clear-cut images of the scales. The hairs can be laid in the celluloid without regarding the depth to which they are immersed. If cover slips are used in the place of slides, the high power of the microscope can be used to better advantage. It is not necessary to fasten the hairs to the cover slip or have the lower surface of the hair in contact with the glass. Only in a few genera is the scale form of guard hairs adequately characteristic to identify the hair with certainty. In these cases it is always the scale form in the basal portion of the hair that is desired. The scales at varying distances along any one guard hair will show a great diversity of form, but the scales at corresponding regions of the same type of hair are fairly uniform in structure. In the species identified by scale structure, it will be found that some hairs have the characteristic scale form for only a short distance near the base. Therefore, when obtaining scale structure, four or more hairs should be imbedded at one time to insure a reliable representation of scale form. 
KEY

It seemed desirable to divide the key into two Divisions. Size relationships between hairs in the two groups is one factor favoring their separation, Division I containing only mammals with fine, relatively short hairs. Their is also a similarity in the manner of occurrence, hairs in Division I practically always being found in considerable numbers, as in feces and pellets. Some of these species are rather abundant and being small, they are generally ingested entire when taken as food, thus accoutting for the abundance of hairs.

The key, it will be noted, consists of a key proper and interspersed Notes which follow each species as it appears in the key. The key proper contains the most distinctive characteristics and aims to keep the amount of time required to identify a hair to a minimum. The "otes consist of supplemental information to help verify identifications. Some of the Notes are of a rather general nature. Thus fur hairs are briefly described as they appear on the middle of the back, no account being taken of the variations at different regions of the body. Moderate use of the key should permit one to ignore the notes in many instances.

Precise instructions as how to proceed to identify a hair sample cannot be given. For longitudinal examination, it is an easy matter to mount several hairs of each type which 
may be present in the sample. This is probably the first step to be taken since some species can be identified thus at once. Scale form is best determined imbedding number of the larger hairs and examining the scale images of these hairs. Scale form should not be judged merely on the basis of one hair. uross sectioning requires more time so that in Division II usually only one hair is sectioned. A general rule is to section a hair of the largest average size represented in the sample.

The most profitable way to familiarize one's self with the key is to first work with known samples, comparing, comparing the cross sections, scales, and medullae with the descriptions in the key. Many features, such as the scales in the genus Mustela, have to be seen but once to be remejbered. A person's own familiarity with the mammals is often helpful. Thus the short, distinctly banded hairs of a ground squirrel would hardly be even considered as belonging to a skunk or muskrat. 


\section{DIVISION I}

This division includes the hairs of the moles, shrews, bats, flying squirrel, mice, and very young brown rats. The hairs of these mammals are short and fine and usually have a silky feeling and appearance. The maximum length is $22 \mathrm{~mm}$. and the maximum diameter 110 micra, but a majority of the hairs will be less than $15 \mathrm{~mm}$. Iong and 60 micra in diameter. These size limits apply only to samples containing several hundreds of hairs. Otherwise a small group of head or leg hairs of other small mammals, such as the least weasel, might be included in this division whereas they are properly placed in Division II.

The hairs often have many nodes and internodes.'The medulla of the fur hairs, when present is discontinuous, The hairs of these mammals are easier to identify than the hairs of many of the larger mammals providing hairs from only one $s$ species are included in the sample. When the hairs of several species are mixed together, numerous xylene mounts are required inprder to make certain that the hairs of all species present are noted.

Samples of the hairs of these small mammals are most of ten found in feces and pellets and usually contain several hundreds of hairs per sample. The key is based on this assumption that a goodly number of hairs are available. Cross sections are obtained not of a single hair but of a representative 
cluster of the largest hairs in the samile. The hairs are imbedded as a group and enough slices are made as are necessary to cut through the region of greatest diameter of the largest hairs. Since it is only necessary to ditermine the shape of the largest cross sections, serial illustrations of the cross sections have not been given.

Hairs from these mammals, especially those considered as buffer species will be encountered very frequently in food habits studies. Pellets of the larger hawks and owls contain the remains of more than one mammal and since the skulls are ejected with the hairs, it is probably easier and more accurate to base the identifieation on the skulls when a large number of pellets are to be analyzed. Skulls give a better quantative analysis since hairs can provide information as to the species present, but not as to the number of individuals present in a single pellet. It would be difficult to detect all the hairs of these small species when the hairs are matted together and well mixed in a pellet, particularly those with circular or o oblong cross sections since practically all species have at least a few hairs with cross section of these shapes. Skulls also make it easy to identify the species in a group, such as the mice, where the hairs appear very similar in structure.

A different problem is presented in feces in which skulls are usually absent, but the halrs are not intermixed to such a great extent. Here hairs must of necessity be used as a basis for identification. 


\section{DIVISION I}

1 Larger hairs of ten having the rodent base . . . . . . 2

1,1 Larger hairs never or only very rarely having the rodent base .4

2 Cross sections of many of the laxger hairs flattened and concave on one side as shown in Fig. 22. $. . \quad \cdot 2,2$

Field mouse, Microtus sp. Deer mouse, Peromyscus sp. House mouse, Mus musculus. Very small brown rats, Rattus norvegicus.

NOTES. Hairs fine, maximum diameter about 80 micra, usually less than $18 \mathrm{~mm}$. in length. Hairs do not have distinct bands of colors. Fur hairs may have nodes and internodes. Medulla at internodes sometimes continuous but usually discontinuous.

2,2 Hairs not with cross sections flattened and aoncave on one side as shown in Fig. 22 .

3 Fur hairs with nodes and internodes. Cross sections of guard hairs always convex, bluntly-oblong to circular as in Fig.23. Hairs usually less than $12 \mathrm{~mm}$. in length and 110 micra in dia. 3,3

Meadow jumping mouse, Zapus hudsonius hudsonius.

3,3 All hairs without nodes and internodes. Outline of largest cross sections convex or very slightly concave on one side as seen in Fig. 24.

Flying squirrel, Glaucomys volans volans.

4. All hairs very fine, usually less than 20 micra in diameter. Hairs without nodes and internodes. Scales usually coronal and are very prominent in some hairs. (Fig. 12). Medulla almost always lacking. $\cdot . ~ 4,4$

The bats, Chiroptera, six species.

4,4 Larger hairs more than 20 micra in diameter. Many of the hairs with nodes and internodes. All hairs with prominent medullae. 
5 Hairs very fine with the distal node greatly enlarged (as seen under high power) in some hairs. Enlarged portion lightly pigmented with brown granules, the medulla lacking or fragmental. Only rarely is the medulla discontinuous in the basal half of the enlarged distal node.

Praire mole, Scalopus aquaticus machrinus.

NOTES. Distal node up to 75 micra in diameter. Cross. sections of the largest hairs convex. All hairs with numerous nodes and internodes. Unenlarged portion of protective hairs and the fur hairs have a discontinuous medulla.

5,5 Hairs not with the distal node greatly enlarged with the medulla fragmental or lacking in the enlarged portion. .

6 Largest cross sections shaped as in Fig. 25. • • . 6,6

Shrews, three species. Soricidae.

NOTES. Mairs usually less than 55 micra in diameter and $10 \mathrm{~mm}$. In length. Medulla discontinuous except at the internodes where it commonly becomes continuous.

6,6 Cross sections of hairs never shaped as in Fig. 25 . Scales at base of guard hairs long and sharly pointed as seen in Fig. 14. Cross sections largest hairs circular.

Star-nosed mole, Condylura cristata. 


\section{DIVISION II.}

This division is concerned with the remaining mamals whose hairs have been arranged in the key somewhat according to the ease of identification: A majority of the wild mammals have hairs with features distinct enough to permit generic or specific classification. In contrast, the hairs of the domesticated mammals are more difficult to describe and identify, both because of the many breeds of animals and because the hairs themselves lack distinctive characteristics. However, with the exception of the dog, these hairs will not be encountered very often in zoological studies. A few hairs of the wild mammals are of such character that they cannot be included in the key. These hairs are the smaller head and leg hairs and the tail hairs of certain species. The medulla is often much reduced in size and the cross sections tend to assume circular or bilaterally symmetrical shapes. Therefore, unless the scales are distinctive, the hairs are very difficult to identify. All hairs which cannot be identified with reasonable certainty have been placed in a miscellaneous group at the end of the key. The combined characters given in the key and more detailed nutes should prevent any hairs belonging to the miscellaneous group from being keyed out in the preceeding part of the key. 


\section{DIVISION II}

7 Hairs fine and exceedingly curly, usually found in a tightly matted mass. All hairs of approximately the sampe diameter. Medulla usually lacking. A greater part of an individual hair is without taper. Scales not conspicuously thickened. • 7,7

\section{Sheep.}

7,7 Hairs not exceedingly curly. Or hairs not very fine. Ur hairs with a wetl developed medulla.

8 Some intermediate hairs in longitudinal view appearing to be made up of squares and rectangles, the sides of which are joined at the corners (Fig. 7). The rectangles lie in distinct longitudinal rows with an occasional row going off at a tangent. A different effect may be seen in other hairs in which the cubical celis themselves can be seen lying in longitudinal rows. Guard hairs do not have these rows of cells, but they are much less numerous than the intermediate hairs so that it would be impossible to obtain a sample consisting only of guard hairs.

Cottontail rabbit, Sylvilagus floridanus mearnsii Snowshoe hare, Lepus americanus sip.

8,8 Medulla in longitudinal view not appearing to be made up of squares and rectangles or longitudinal rows of cubical cells.

9 Guard hairs with long-pointed scales extending to a variable distance from the base (Fig. 14). In some hairs the scales may be more blunt pointed but can still be recognized as Mustela by a few scales (Fig. 15) which will have very straight edges and a sharp point. Cross sections usually oblong and bilaterally symmetrical.

Mink, Mustela vison mink.

Least weasel, M. rixosa alleghensis.

New York Weasel, M. n. noveboracensis.

NOTES. Hairs never banded. Medulla nodose continuous except at the very tip where it becomes discontinuous. A few tail hairs may be circular in cross section and without the characteristic scales. 
9,9 Guard hairs not with lon pointed scales in the basal portion of the hair; or hairs with irregular cross sections or with distinct bands of colors.

$\therefore 10$ Outline on cross sections concave on one side for at least $1 / 6$ of the length of the hair. Hairs often having the rodent base. Or scales at the base of the larger hairs similar to those shown in Figs. 16 and 17. for at least a distance of 200 micra. . . . . 11

NOTES. Tail hairs of the chipmunk have scales somwhat similar to this, but they do not occur to a distance of 200 micra along the shaft. A very few guard hairs of the fox may have cross sections concave on one side for a short distance, but the medulla is homogeneous continuous and the scales at the base of the hair may be similar to those in Fig. 18. Pile hairs of the rabbit have scales similar to those in Figs. 16 and 17, but the very distinctive medulla should prevent their being placed in this group. Cross sections of rabbit hairs may be concave on one or two sides.

10,10 Outline of cross sections not concave on one side for at least $1 / 6$ of the length of thehair, scales never as in Figs. 16 and 17.

11 Scales at base of guard and intermediate hairs similar to those shown in Figs. 16 and 17.

Red squirrel, Sciurus hudsonicus loquax. Gray squirrel, S. carolinensis leucotis. Fox squirrel, s. niger rufiventer.

NOTES. Fur hairs have a discontinuous medulla and a pigmentless cortex. Many of the hairs have cross sections concave on one side in the basal portion of the hair. The darkly pigmented guard hairs have the typical scales, but the cross sections are oblong and convex in outline.

11,11 Scales at the base of the guard or intermediate hairs not similar to those shown in Figs. 16 and 17. 
12 Cross sections concave on one side for practically the entire length of the hairs, such as in Figs.26827.

Ground squirrel, Citellus t. tridecimlineatus.

NOTES. Fur hairs commonly without a medulla. Some may have a few eragments of one or a discontinuous medulla for a short distance near the tip of the hair. Cortex has numerous pigment granules.

12,12 Cross sections not concave on one side for practically the entire length of the hair.

13 Scales at base of hair pitenfeconspieuous in a xylene mount and roughly appearing diamond shaped (Fig. 19). Cross sections of basal portion of hair much flattened and concave on one side as in Fig. 88.

Brown rat, Rattus norvegicus.

NOTES. The brown rat also has a set of longer guard hairs which have the same scales at the base, but the cross sections are circular. These darkly pigmented hairs are very similar to some leg hairs of the skunk.

13,13 Cross sections basal half of hair not as in Fig. 28. scales at base of hair not as in Fig. 19.

Southern woodchuck, Marmota monax monax. Rufescent woodchuck, monax rufescens.

NOTES. Cross sections of of basal and distal third of hair elliptical while the mid-region has cross sections concave on one side as in Fig. 29. Other hairs with the basal half of hair having cross sections concave on one side while the cross sections of the distal half are elliptical. Many hairs have a white band about $5 \mathrm{~mm}$. Iong near. the tip of the hair with pigment granules in the extreme tip. Such white tipped hairs with pigments in the extreme tip are found only in the woodchuck and the ground squirrel, but the tail hairs of the ground squirrel are concave on one side for most of the length of the hair. Some belly hairs may have a very clear diffuse reddish pigmentation which is very characteristic although the cross sections are convex. 
14 Many hairs with the rodent base. Cross sections very regular, being elliptical in the basal half and circular in the distal half (Fig. 30). Cortex of many fur hairs without pigment granules but may contain scattered air spaces.

Chipmunk, Tamias striatus lysteri.

NOTES. Hairs short, rarely more than $20 \mathrm{~mm}$. lone. Tail hairs are circular or nearly so in cross section. Some fur and intermediate hairs have a diffuse pigmentation in the distal end. Cortex in fur hairs is relatively thin.

14,14 Cross sections not regularly elliptical in the basal portion and circular in the distal portion. Hairs usually without the rodent base.

15 Medulla small (Fig. 5), usually less than $1 / 3$ as wide as the hair. Cortex has numerous pigment granules ranging from light to dark brown, lying in longitudinal streaks. In the lighter pigmented hairs, numerous irregular chambers can be seen in the medula. The walls of the chambers have a high luster where they adjoin the cortex. Cross sections narrowly elliptical and bilaterally symmetrical as seen in Fig. 31, • ${ }^{\prime} \cdot 15,15$

Muskrat, Ondatra zibethica.

15,15 Cross sections not as in Fig. 31 with a small, nodose continuous medulla, or hairs with distinct bands of colors.

16 Larger hairs all white, medulla continuous, grayish, and of ten irregular in cross section (Fig. 32). Scales fairly conspicuous in xylene mount. vortex of fur hairs without pigments in the basal $2 / 3$ of the shaft. There is a set of smaller intermediate hairs with dark pigment granules. These hairs are often enlarged only in the distal half. uross sections distinctly flattened on on side as in Fig. 33 .

Opossum, Didelphis virginianus virginianus.

16,16 Medulla of white hairs never with lobes as in Fig. 32. Intermediate hairs not with cross sections flattened on one side as in Fig. 33 . Or hairs with more than two bands of colors. 
1717 Medulla composed of distinct chambers, roughly hexagonal in shape as seen in Fig. 20. Under high power the walls of the chambers have a high luster where they come in contact with the cortex. In most hairs the cortex is very thin with the medulla occupying almost the entire shaft.

White-talled deer, odocalleus virginianus borealis.

NOTES. Cross sections circular to oval. In small hairs from the head and legs, the cortex may be thicker, but the medullary chambers are still distinctive. Hairs may be over three hundred micra in diameter.

17,17 Medulla not with distinct, clear-cut chambers, roughly hexagonal in shape or the cortex is never so thin as to be practicaliy invisible.

18 Cross sections elliptical and bilaterally symmetrical with a relatively thick cortex as seen in Fig. 34. Intermediate hairs with symmetrical scales in the basal portion of the hair as seen in Fig. 2l. Medulla homogeneous continuous and coarsely granular. As viewed longitudinally, the edges of the medulla are often not parallel to the edges of the hair. Hairs never all white. wedulla of fur halrs generally lacking or fragmental, rarely discontinuous. Cortex with numerous pigment granules. An excellent point to be observed in the cross sections of some of the darkly pigmented hairs is a narrow strip of pale yellow at the periphery of the cross section.

Raccoon, Procyon lotor lotor. 
The remaining hairs are the most difficult to describe and identify. The miscellaneous group includes hairs of the following species:

1. Badger, Taxidae taxus taxus.

2. Skunk, Mehitis nigra.

3. Fox, Vulpes fulva.

4. Coyote, vanis latrans.

5. Dog, L. familiaris.

6. Cat, Felis domestica.

7. Cow.

8. Horse.

9. rMan.

10. Pig.

11. Tail hairs of the squirrels, Sciurus.

12. Tail hairs of the chipmunk, Tamis striatis lysteri.

13. Some of the tail hairs of the raccoon, Procyon 1. lotor.

14. Some tail and belly hairs of the woodchuck, Marmota spp. \$5. Small head and leg hairs of all species.

It does not seem possible to describe these hairs in key form. There is too much similarity between various hairs of certain of these species. In several of the species, each Individual may have many different kinds of hairs. Thirdly because the hairs themselves have neither scales, cross sections,

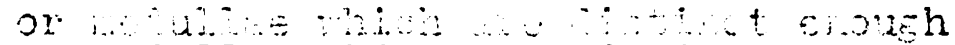
or medullae which are distinct enough to describe and permit 
positive identification. Usually numerous combined characters must be taken into consideration in order to identify these hairs, when it is at all possible to do so. Many of these hairs can, however, be identified by comparison or through personal familiarity with the hairs. Notes are given for some of these hairs which may help identify the species.

Hairs all white, all brown, or with two or three bands of brown and white. Large guard hairs stiff and bristle-like. Some of them, when observed under the microscope, are seen to have nodes and internodes in the basal portion. Medulla homogeneous continuous. Cross sections of ten irregular in shape as seen in Fig. 35. Some hairs with most of the cross sections regular and oblong with a slit-like medulla.

Fur hairs with a discontinuous, fragmental, or continuous medulla, usually less than $1 / 3$ of the width of the hair. Cortex of many fur hairs is without pigment granules.

\section{Badger, Taxidae taxus taxus.}

Hairs all white, all dark brown, or rarely with a band of brown and white. medulla is homogeneous and finely granular, but often concealed in the darkly pigmented hairs. Cross sections all oblong, all circular, or circular in the basal portion and oblong in the distal portion. Fur hairs white or with brown pigment granules in the cortex. Medulla about $1 / 3$ as wide as the hair.

Skunk, Mephitis nigra.

Intermediate or small guard hairs with scales as seen in Fig. 18. Wedulla homogeneous. Fur hairs with a discontinuous medulia. uross sections circular to oblong, sometimes flattened on one side. These hairs will not be confused with the opossum because the cross sections are circular in the basal portion while in the opssum they are flattened at the base of the hair.

Fox, Vulpes fulva.

Coyote, Canis latrans. 


\section{LITERATURE CITED}

(1) Allen, J.A. 1894. On the Seasonal Changes of Color in the Varying Hare (Lepus americanus Erxl.). Bull. Am. Mus. Nat. History. VI:107-128.

(2) Boyd, Eviyn. 1932. The pigmentary System and the Dopa Reaction. Proc. Roy. Soc. Ed. 52:218-235.

(3) Grange, Wallace B. 1932. The Pelages and Color Changes of the Snowshoe Hare, Lepus americanus phaeotus, Allen. Journ. Mamm. 13:2, pp. 99-116.

(4) Gunn, Charles Kenneth. 1932. Color and Primeness in Variable Mammals. Am. Nat., vol. 66, pp. 46-559.

(5) - 1932. Phenomena of Primeness. Can. Journ. Research. vol. 6, no. 4, pp. 387-397.

(6) Hadwen, Seymour. 1929. Color Changes in Lepus americanus and other Mammals. Can. Journ. Research. 1:189-200.

(7) 1934. Color Changes in Snowshoe Hares. Can. Journ. Research. vol. 10, no. 5, pp. 539-556.

(8) Hardy, J. I. 1932. A Method for Studying the Scale Structure of Medullated and Pigmented Animal Fibers. Journ. Tex. Ins. 23:T1-T5.

(9) Hausman, Leon Augustus. 1920. Structural Character istics of the Hair of Mammals. Am. Nat. 54:496-523.

(10) - 1924. Further Stidies of the Relationships of the Structural Characteristics of Mammalian Hair. Am. Nat. 58:44-57.

(11) - 1930. Recent Studies of Hair Structure Relationships. Sci. Mon. vol. 30, no. 3, pp. 258-277.

(12) Manby, J. 1932. An Improved Method for Revealing the Scale Structure of Wool and Hair. Journ. Tex. Ins. 23:T5-T13

(13) 1932. II. Celluloid Impressions of the Surface Structure of Animal Fibers. Journ. Royal. Mic. Soc. London, (3) 53:9-12. 


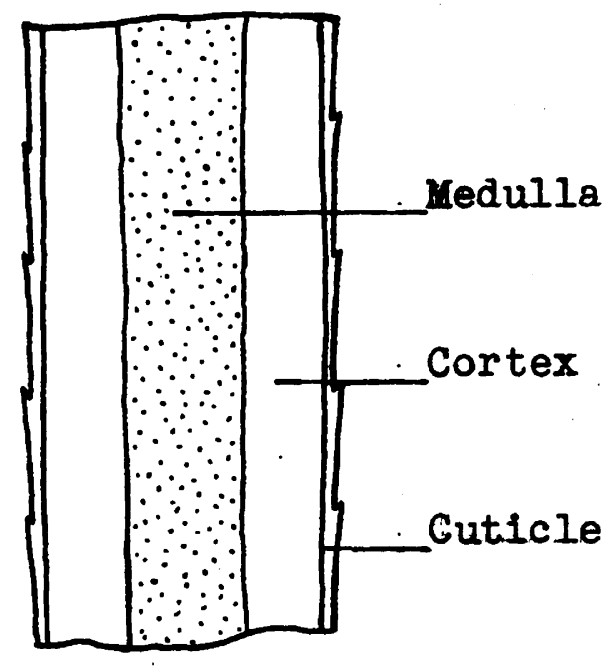

Fig. 1. Diagram of a longitudinal section of a hair shaft.

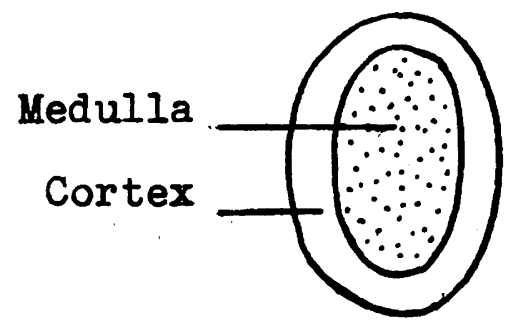

Fif. 2. Diagram of a cross section of a hair. Usualiy the cuticle is too thin to be seen in cross section.

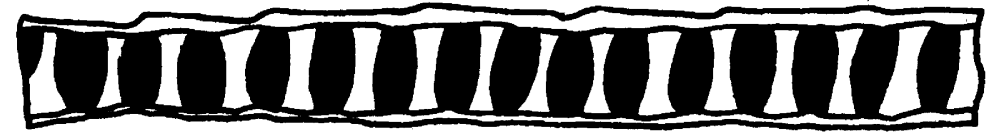

Fig. 3. Discontinuous medulla of a fur hair with a relatively thin cortex.

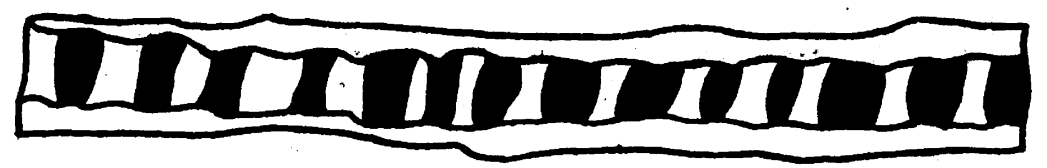

Fig. 4. Discontinuaus medulla of a fur hair with a relatively thick cortex. 


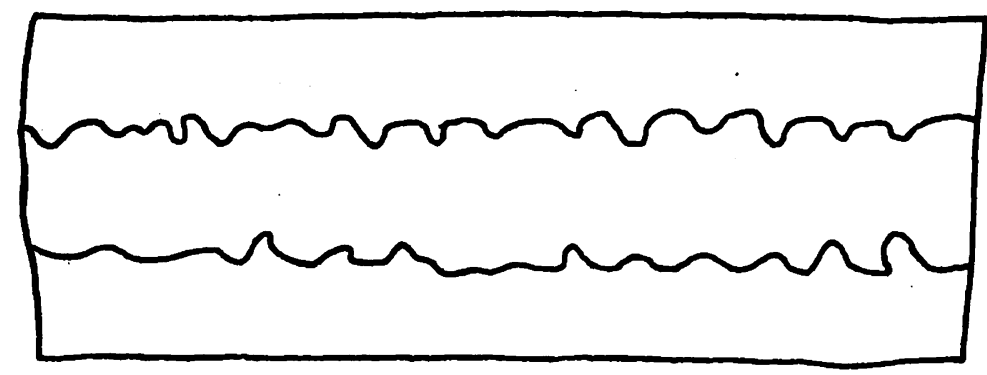

Fig. 5. Outline of a nodose continuous medulla of a muskrat guard hair.

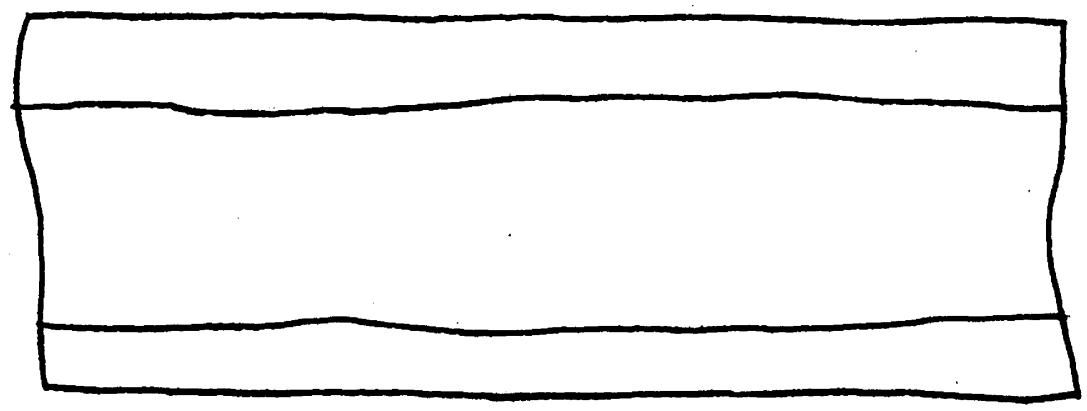

Fig. 6. Outline of a homogeneous continuous medulla.

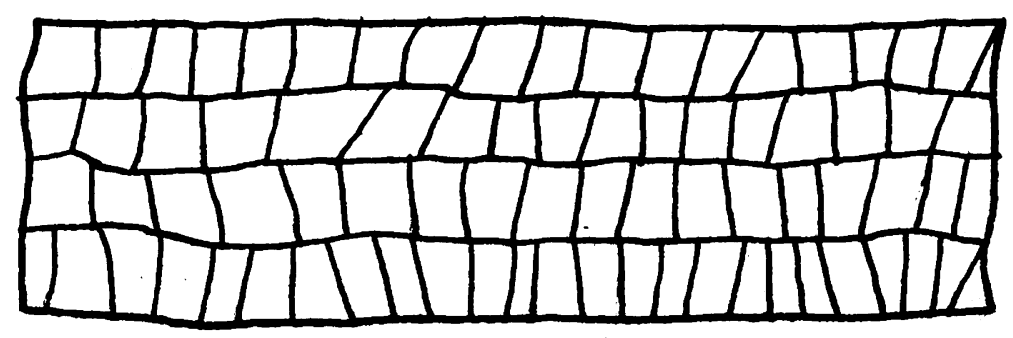

Fig. 7. Rabbit intermediate hair with a chambered medulla and a thin cortex. 
Fig. 8. Fragmental medulla of a human hair.

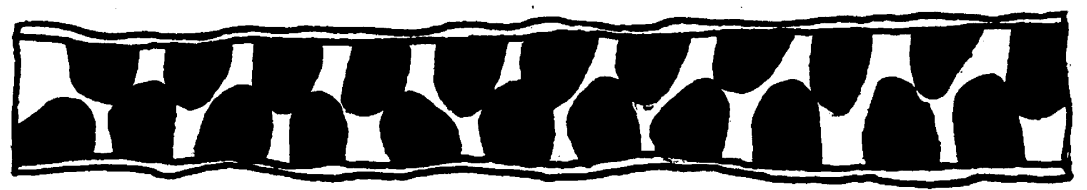

Fig. 9. Compound medulla or one type of the rodent base.

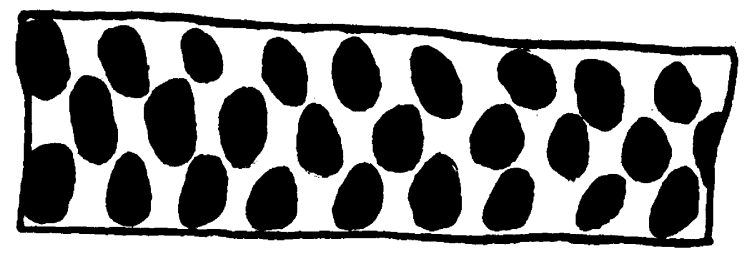

Fig. 10. A compound medulla

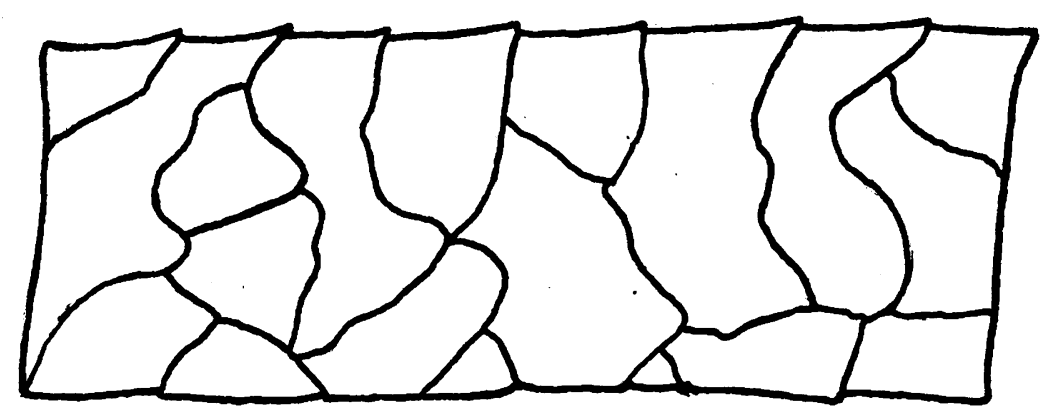

Fig. 11. Imbricate scales of a fox hair. 


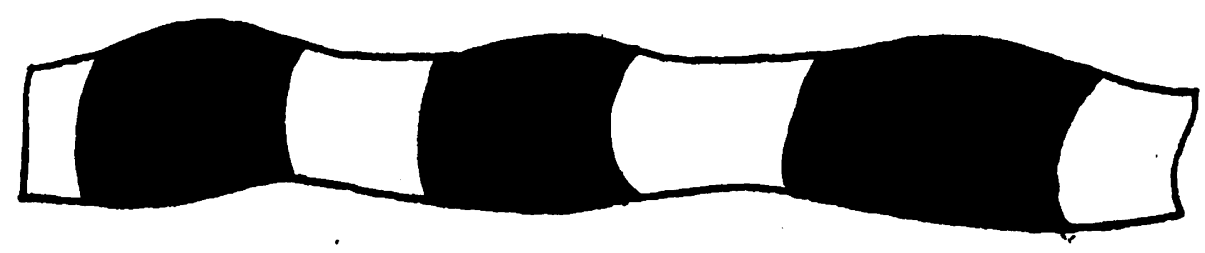

Fig. 12. Heavily pigmented coronal scales of a bat halr.

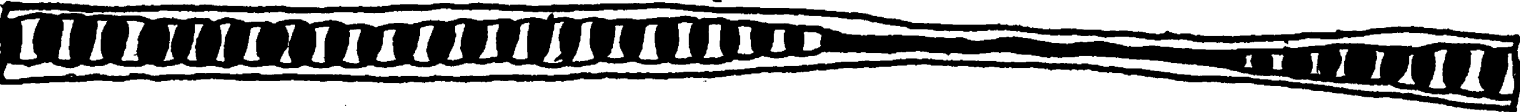

Fig. 13. An internode having a continuous medulla with a portion of two nodes.

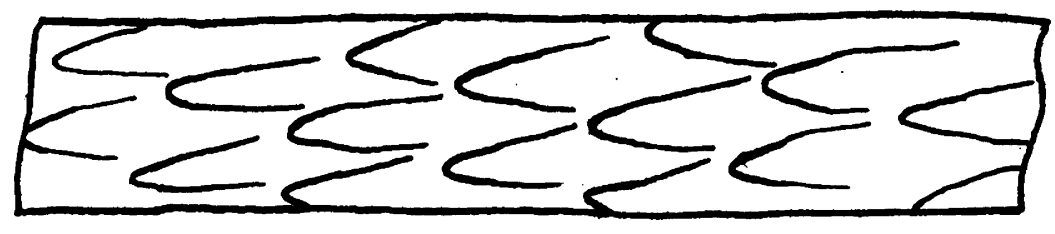

F1g. 14. Long-pointed scales such as are found in some hairs of the starnosed mole and members of the genus Mustela.

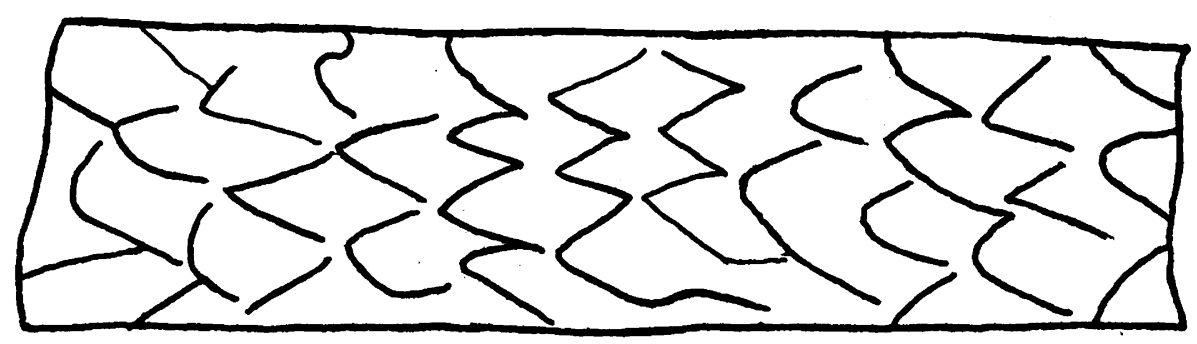

Fig. 15. Sharp, pointed scales found in some hairs in the genus Mustela. 


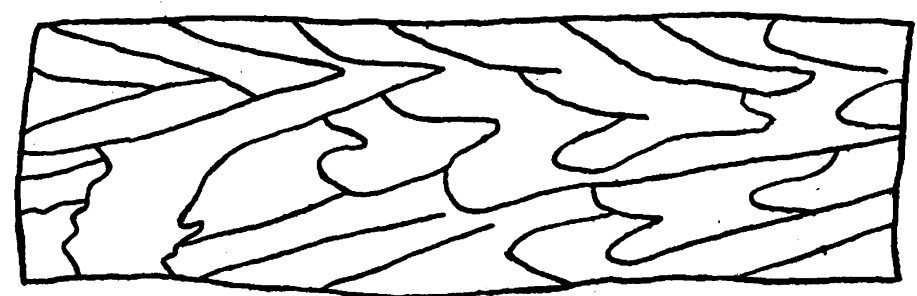

Fig. 16. Scales of certain hairs of the squirrels, Sciurus.

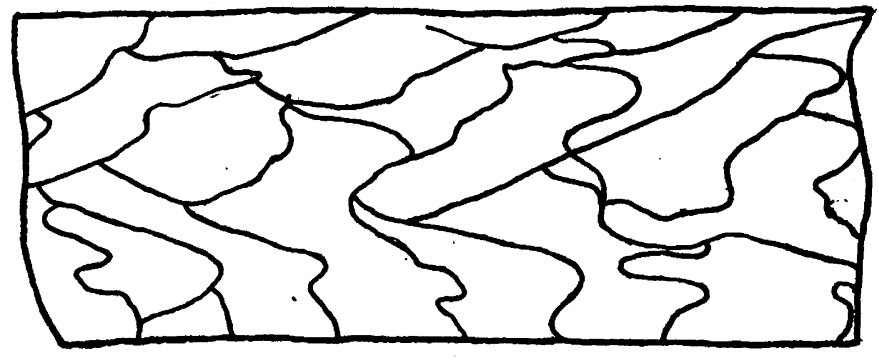

Fig. 17. A variation in the scales of squirrel hairs.

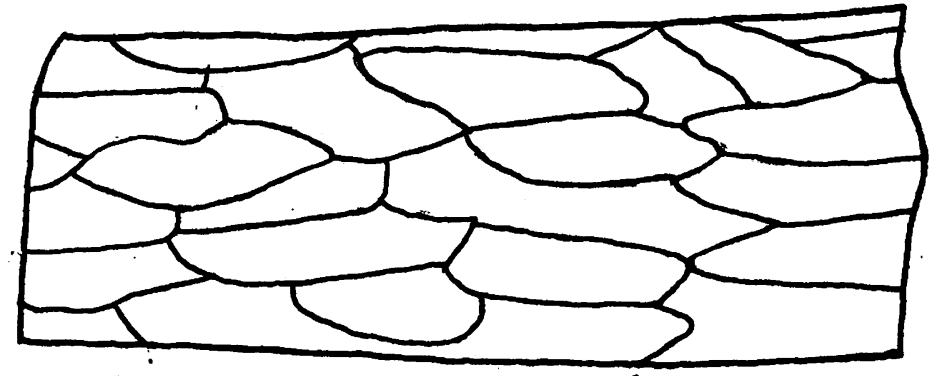

Fig. 18. Scales as seen in some hairs of the fox and coyote. 
$-35-$

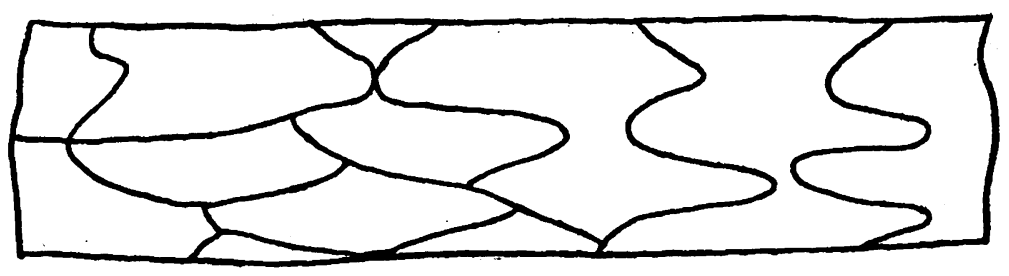

Fig. 19. Roughly diamond shaped scales of the brown rat.

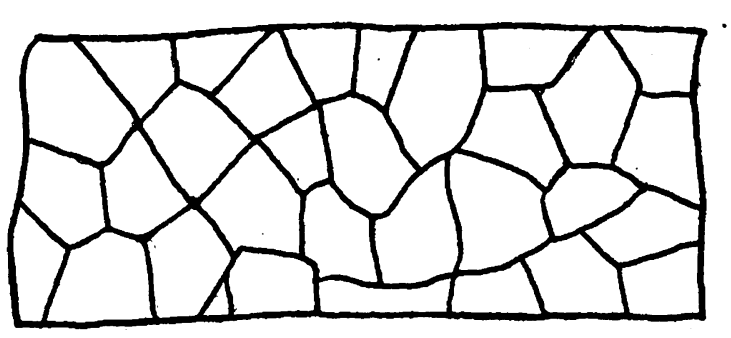

Fig. 20. Roughly hexagonal shaped chambets in the medulla of a deer hair.

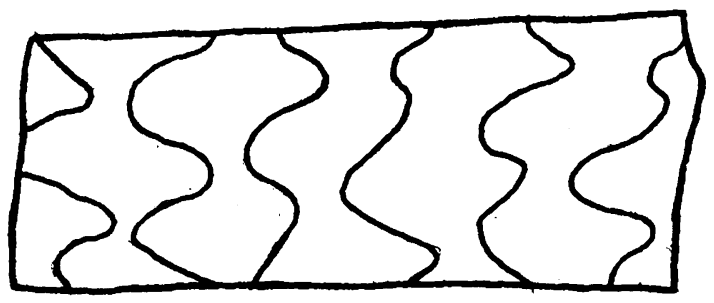

Fig. 21. Scales of an intermediate hair of the raccoon. 


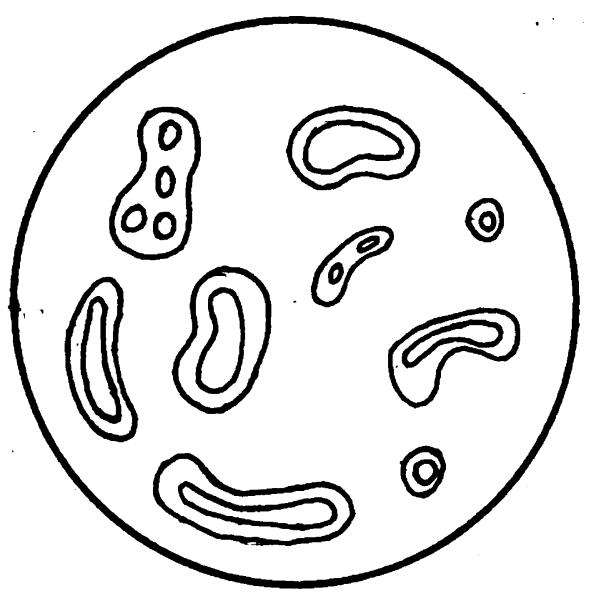

Fig. 22.' Characteristic cross' sections of field mice, deer mice, house mice, and very young brown rats.

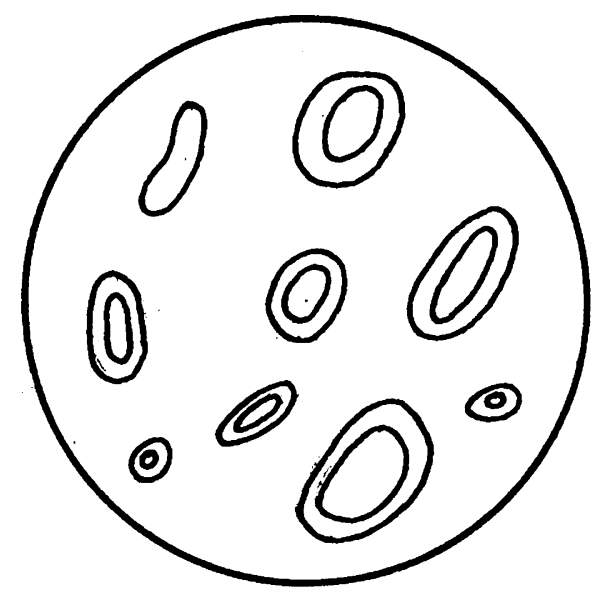
Fig. 24. Cross sections of
body and tail hairs of the flying squirrel.

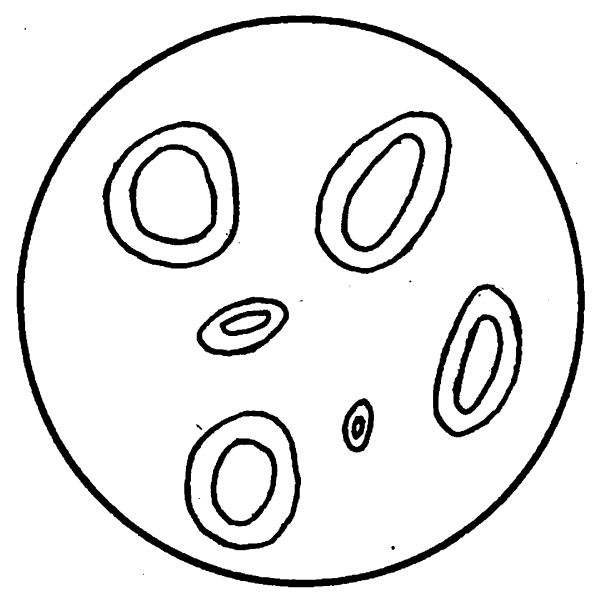

Fig. 23. Cross sections ' of guard hairs of the jumping mouse.

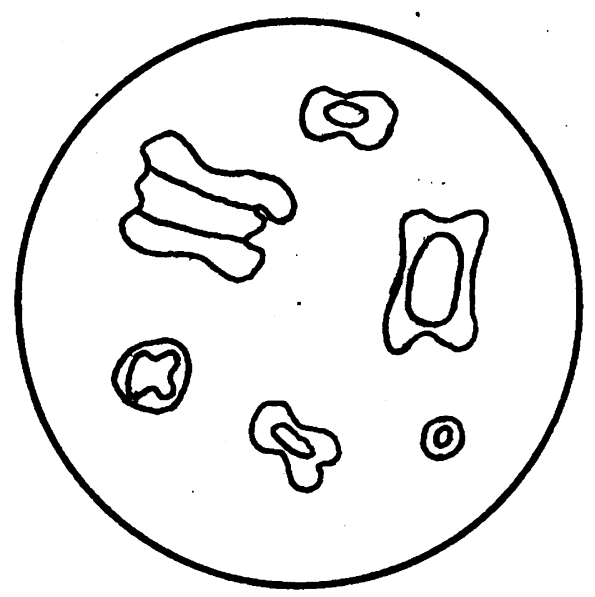

Fig. 25. Distinctive cross sections of shrew hilrs. 


\section{$000(8)(3)(2) 0$}

F1g. 26. Back hair of ground squirrel.

\section{(0) (0) 80008800}

Fig. 27. Tall hair of a ground squirrel.

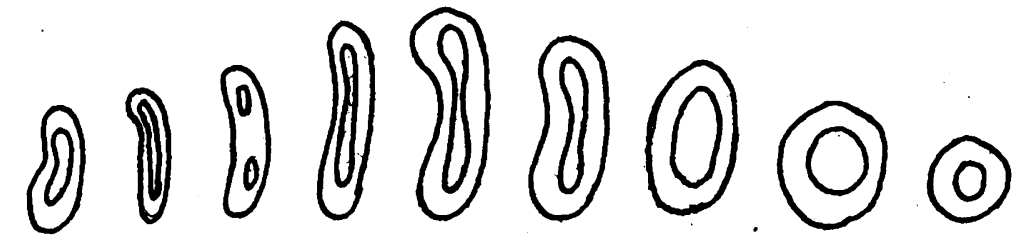

Fig. 28. Intermediate hair of the brown rat.

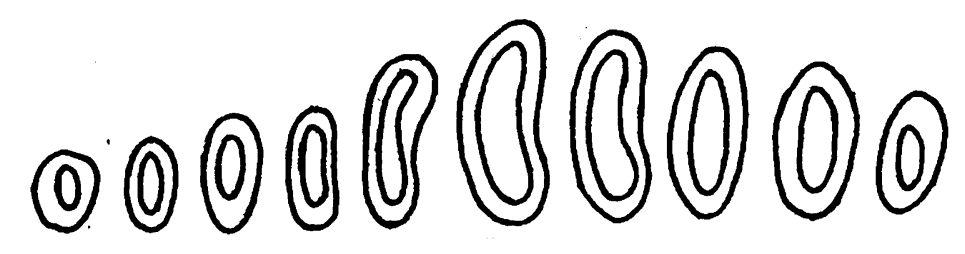

Fig. 29. Guard hair of the woodchuck.

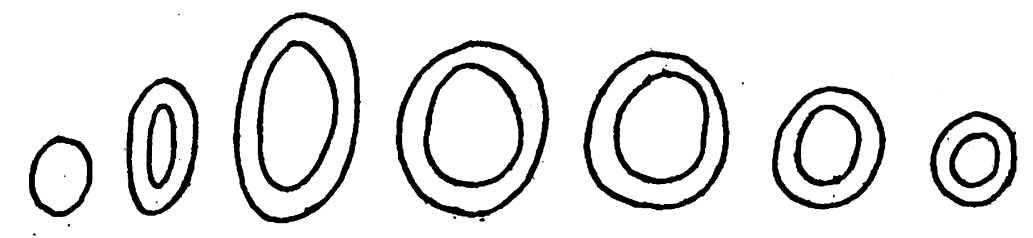

Fig. 30. Guard hair of the chipmunk. 


\section{0}

Fig. 31. Guard hair of the muskrat.

$000(0)(0)(3)(3)$

Fig. 32. Large white guard hair, opossum.

0000000000

Fig. 33. Pigmented intermediate hair, opossum.

๑०(0)(0)(0) ๑०

Fig. 34. Guard hair of the raccoon.

(0) (0) (1) (1) (0) (3) (1)

Fig. 35. Guard hair of the badger. 
APPENDIX

\section{A Rapid Mothod of Cross-Sectloning Mammalian Hairs}

Harold 1. Mathiak

Haix samples are frequently oncountered in connection Wth 11 fo history studies, food habits research, and in 1s0lated cases of mortality observed in the flold. Cross sections of the halrs often prove of metorial value in determining the Identity of the mamal involved. In come manals, for examplo the shrews, the shape and strueture of the orosa sections of the halrs are much more distinctive than the appearanes of the hair es viowed longttudinally. Especially is this twue whon 1t 1s known from whloh portion of the hals the cross sections are obtained.

Sereral mothods of eross-sectloning halrs have been used in the past, the most intricate being the use of rotary or llding miorotames. Howerer, many workere do not have access to mforotomes, and furthermore, the amount of time required by the microtome mothod is far too long for practical purposes. 1 Hardy montions Hotte's method of bullding up euceesalve layers of colloldin, bayberry wax, and paraffin about individual hairs in order to section them. Dearborn' rolled softened parafin botwoen the pains of the hands, forming a oylipdor. Tho oylinder was out lengthwlee, halre were inserted betwoen the

1. This mothod 1s discussed in dotall in Guyor's (1) Animni M1crology.

2. From verbal description of the mothod by H. H. Wight. 
halves which were flrmig pressed together again, sectlons then boling sliced with a razor blade.

Williams (3) describes mothod dereloped and used at tho Food Habits Research Laboratory, Denver, Colorado, by which Individual hairs can be sectioned. The pith from the stom of a plant, such as ragreed, 1s split lengthwise, and the halrs are placed betwoen the halvos parallel to the longl tudinal axis. The haltes are soaled together with gum-arab10 mucllage whloh is allowed to dry. Sections are thon out with a sharp razor blade. Those sectlons can bo mounted in Canada balsam for microscopic examination.

Recentiy an effloiont, modified microtome with which an exporienoed operator can obtain cross sections of fibere in ten minutes was invented by Hardy (8). A group of flbors 18 washed in alcohol or other, driod with blotting paper, and placod in a rectangular slot in holder of the motill1c derloo which is so constructed that the olump of fibers can be projocted through the slot to any desired distance. Colored oelluloia solution is applied to the onds of the r1bors and allowd to dry, after which the sections of fibers and celluloid are cut off with a sharp razor blado and mounted in canada belsam. By means of a sorer propeller, the fibere are caused to project out to the desired distance for outting, another couting of collulold 18 appl1ed, and the process repeated. 3 The instrumont was in-

3. Dlagrams and more complete explanation of hor the derlce operates is to bo found in Circular (2) Ho. 378, U.S.Dept. Agriculture. This instrument is now avallablo at a price of $\$ 35$. 
tonded primerily for the study of fibers used in the text1le Industry and is admirably sulted for that purpose since large numbers of cross sections of each sample of flbers are wanted. Sections may bo out so thin that oren tho shape of pigmont granules can be seen.

In the course of present studen the wher has doreloped a now technique for oross-soctloning halrs which sowe satisfactory. It works equally well for one or sereral balrs of any 180. They are visible during the ontire operation so that cross sections of any desired portion of a single halr can be taken. Gaard halrs exhlbit much more individuality then sur halrs, and sinee the shape of the oross sections of guard hairs may rary wdely from base to t1p, it 1s essontial that the region from which the cross sections are cut be known.

The method 18 inexponsive, requiring razor blades, a pink solution of colluloid in sectone, and balse wood, the lattor purchasable at stores carrying model alrplane supplies.4 whle different pleces of balse wood may raxy in bardness, none of it 1s too bard to out with a rasor blade. Whon it is desired to section small individual halrs, tho long strips of wood can be out Into stioks about four Inobes long and haired longltudinally With a rasor blado.

In making the collulo1d colution, firati dieselve a red or pink dye (these colors apparentiy gire the best results) in acotone, and then add pieces of oellulold unt1l the solution

4. In Ann Arbor strips of belsa wood $1 / 8 \times 1 / 4 \times 18$ inches cost one cont each. 
is of the right consistency. There can be considerable range in the viscosity of the solution, thin solutions oraporating faster and thicker solutions holding the halrs more firmly. The solution should be colored only a very pale pink, for the dye will become more concentrated when the acotone is allowed to eraporate. Too much dye in the cellulold interferes with transmission of the $11 \mathrm{ght}$ and reduces definition. Congo red, carmine, or any red dye is sultable. Dyes not soluble in acetone oan be added after bolng flrst dissolrod in alcohol. The collulold solution is most conroniently kopt in a small, tightiy stoppered bottle in which a brum is attached to the stopper. Finger-nall polish can be substituted for the collulold solution by those wanting to section only a fow halrs.

Imbodding 1s accomplished by placing a costing of cellulold on atiok of balse mood, and then laying tho hairs on the stloky solution parallel to the long axis of the stick as seon In F1g. 1, A. Additional cellulold is placed on top of the halrs and allowed to dry. The seotions can be slloed in fram fire to ten minutes, depending on the amount and viscosity of the solution used. Hardening of the cellulold cen be hastened by mildiy heating it orer an electric lamp after most of the acetone has eraporated. Heat cannot be appliod Immediately because of the formation of lerge bubbles. No time will be lost walting for the oellulo1d to hardon if five or more samples of halr are imbedded before any seotioning is done. 
A razor blade held in a vertical plane is used with a slicing motion to out through tho colluloid, hairs, and wood. Sections (ahaped as in F1g. I, B) can be varied from throe-tenths to one mililmeter in thickmess, six-tenths mililmeters being generally most sultable.5 The sections are arranged in serial order on a side and examined under a microscope with transmitted light. A thin fiIm of oil on the silde will prevent any dis turbance of the extremely light pieces of balsa wood. Iong halrs can be out into horter lengths wich, if imbedded in consecutive order, will give serial seetlons of the entire halr.

Although low power alscloses structural fentures oufficiently well in most instanees, high pores can be wed for the examination of the smaller hairs and in the event that measurements are to be taken with an ooular mierometer. Small halro w11 be found imbodded ontirely within the cellulold while very large hairs may project above the gonoral lovel (F1g. I, C) since the solution greatiy dearcased in volume upon drying. In olthor oase tho oellulold 18 so rgid that the oross sections are obtained without distorting the halr. The celluloid is colored a Ilght pink to differentlate it from the rood and to 1mprove optical effects. A brilliant illumination with the collulold and hais to one side of the mierosoople fleld, as shown in F18. 1, D, gives the bost definition, the rood eutting out much of the light and proventing oye strain. Clearing the

5. Thinner sectlons seem to be better for white or densely plgmented hairs. 
hairs with an oll is not nocessary, the medulla, cortex, and character of the pigmentation belng discprnible in the sections as out. Cross sections from specimens of known 1dentity can be filed in small vials for future reference.

\section{References}

(1) Guyer, Micheol F. 1936. Animal Mlorology. The University of Chlcago Press, Chicago, Illinols, pp. 38-76.

(2) Hardy, J. I. 1935. A Pract1cal Laboratory Method of Making Thin Grose Section of Flbers. Cireular No. 378, U. S. Dopt. Agr. pp. 1-10.

(3) Williams, Cocil s. 1934. A Simple Method for sectloning Mamailan Hairs for Identifloetion Purposes. Jour. Marm., vol. 15, no. 3, pp. 251, 252.

Harold A. Mathlak,

School of Forestry and Conservation, University of Miohigan.

Ann Arbor, Mlchigan. 

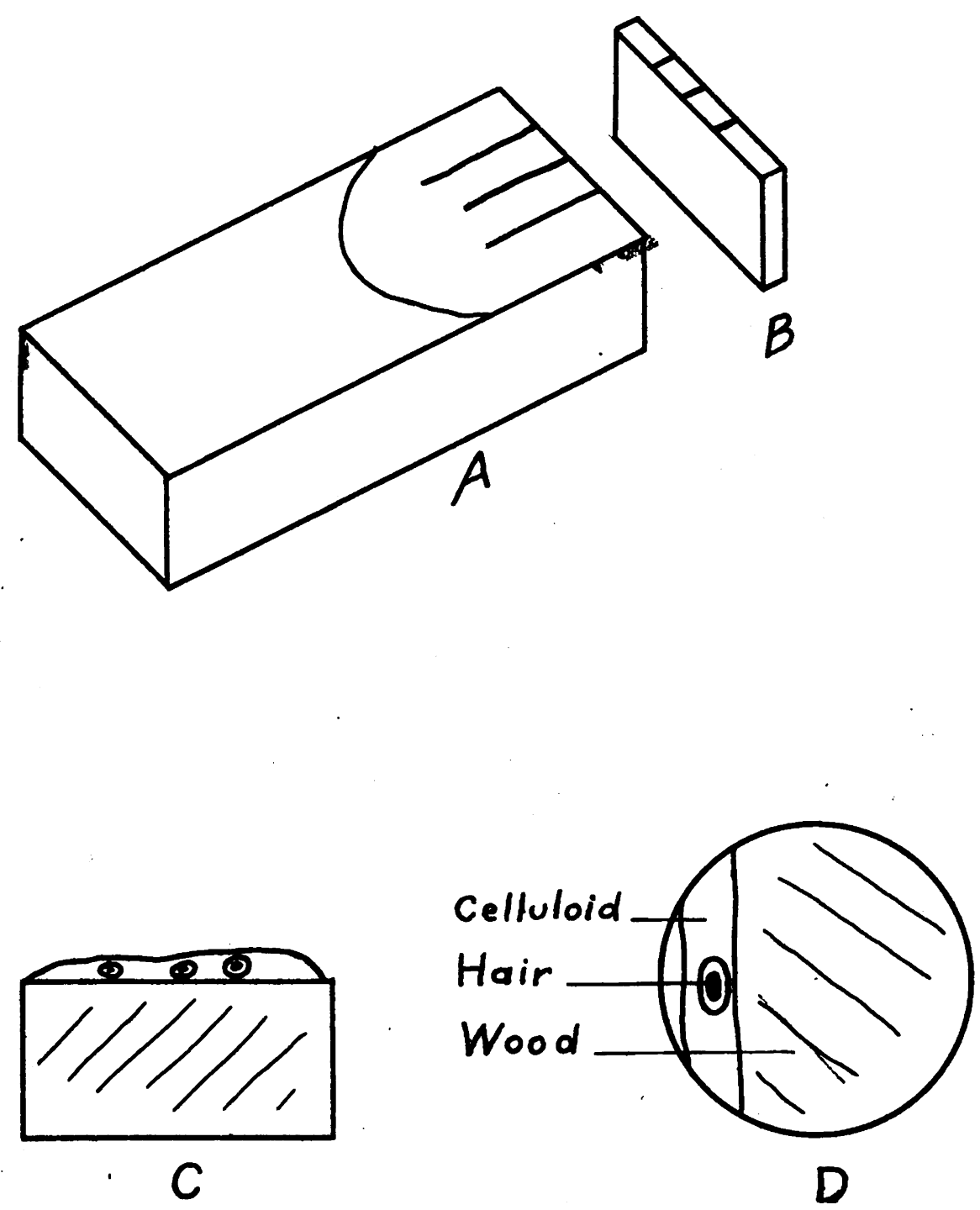

Fig. 1. A, Smail stick of balsa wood showing hairs in celluloid, $X 2$; $B$, a section as cut off, $X 2$; $C$, same section $X 3$ with size of hairs exaggerated; $D$, diagram of a section as it appears in the microscopic field. 


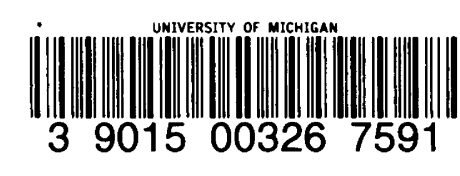



1.8.

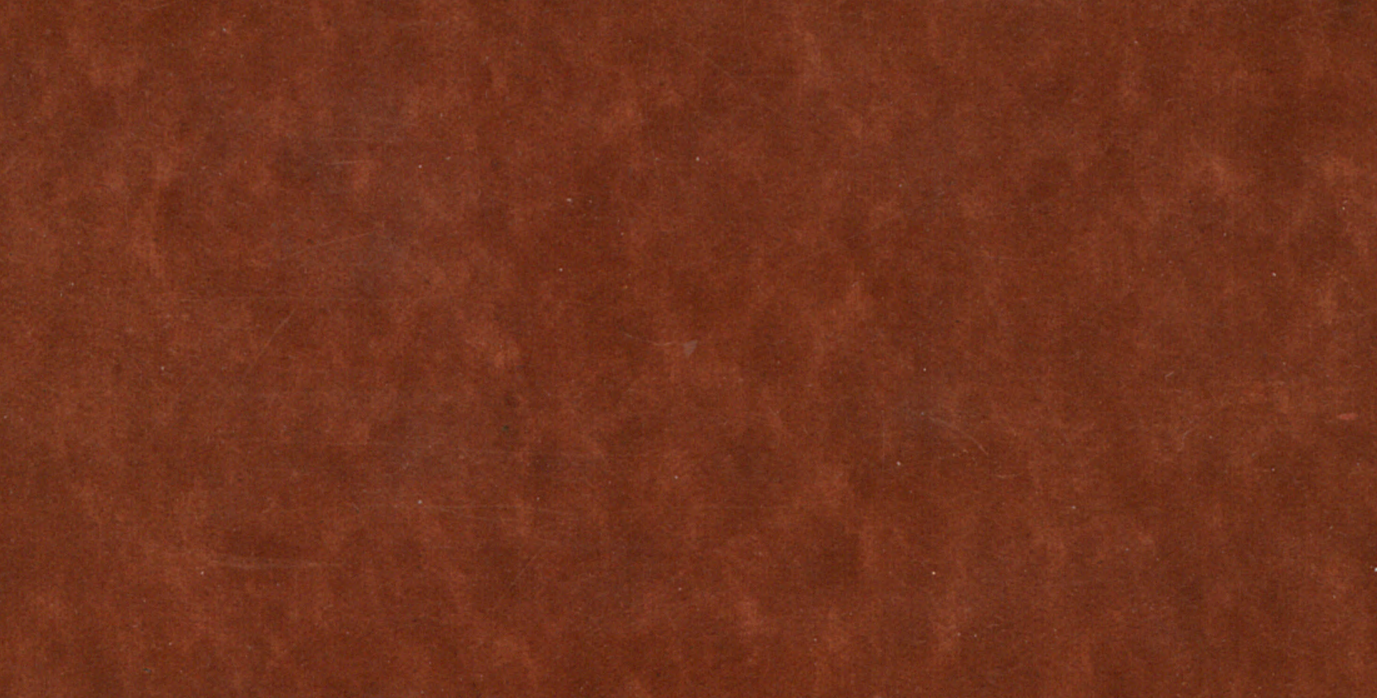

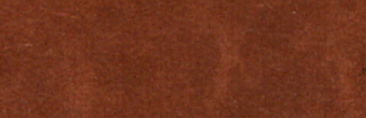

25

$\therefore$
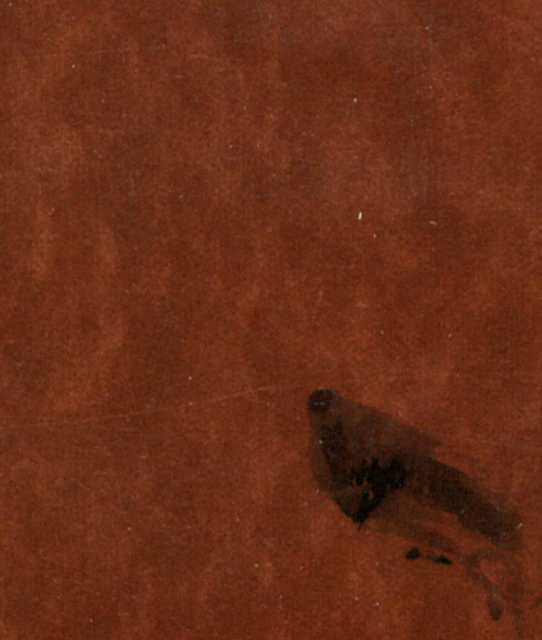

4 